\title{
O estágio supervisionado em comunidades etnoeducacionais indígenas e quilombolas: um ensaio sobre a questão curricular nos anos 2000
}

\author{
Leonara Lacerda Delfino ${ }^{1}$
}

\begin{abstract}
RESUMO
Este artigo tem por objetivo tecer balizas acerca da construção normativa curricular em torno da questão afroindígena e seus impactos, desafios e exigências para a formação do professor do Ensino Básico em comunidades etnoeducacionais e quilombolas. Pretende-se problematizar os papeis do estágio supervisionado neste processo de formação docente junto às políticas públicas de inclusão e de combate ao racismo estrutural presente dentro e fora do espaço escolar. Como fontes investigativas foram consultadas as legislações referentes às políticas educacionais e à reforma curricular pós-ditadura militar, tais como: a Lei de Diretrizes e Bases da Educação (Lei 9394/96), os Parâmetros Curriculares Nacionais (PCN, 1998), as leis identitárias (10.639/2003 e sua reformulação 11.645/2008), as Diretrizes Curriculares Nacionais para a Educação das Relações Étnicorraciais e para o Ensino de História e Cultura Afro-Brasileira e Africana (2004), dentre outros textos normativos.

Palavras-chave: formação docente, cultura afro-brasileira e indígena, comunidades etnoeducacionais e quilombolas.
\end{abstract}

\begin{abstract}
The purpose of this article is to provide guidelines on the normative curricular construction around the Afroindigenous question and its impacts, challenges and requirements for the formation of the Basic Education teacher in ethnoeducational and quilombola communities. It is intended to problematize the roles of the supervised internship in this process of teacher training with the public policies of inclusion and fight against structural racism present inside and outside the school space. As investigative sources, the legislations regarding educational policies and post-military dictatorship curricula reform were consulted, such as the Law on Guidelines and Bases of Education (Law 9394/96), National Curricular Parameters (PCN, 1998), laws (10,639 / 2003 and its reformulation 11.645 / 2008), the National Curricular Guidelines for the Education of Ethnicoracial Relations and for the Teaching of AfroBrazilian and African History and Culture (2004), among other normative texts.
\end{abstract}

Keywords: teacher training, Afro-Brazilian and indigenous culture, ethno-educational and quilombola communities.

\footnotetext{
${ }^{1}$ Pós-doutoranda em História pela Universidade Estadual de Montes Claros (UNIMONTES), com a pesquisa financiada pela CAPES, intitulada por: "A (in)visibilidade do 'outro': Os desafios para a construção da cidadania no ensino de história, através das ações do PIBID nas escolas públicas.”. Email: leonaralacerda@yahoo.com.br.
} 


\section{Introdução: o currículo como espaço de disputas}

A construção social do currículo - tema estudado por Sacristán (1999) e Goodson (1995) - pressupõe sempre um campo de lutas, onde diferentes lugares de fala de sua composição - políticas públicas, universidade, escola, professores, editoras de livros didáticos - se confrontam para defender seus projetos de educação e de sociedade, nem sempre congruentes entre si. Nesse sentido, o currículo não se constitui como um processo neutro, desvinculado de interesses governamentais, sociais, econômicos e culturais do seu tempo.

O currículo pode ser entendido em suas modalidades: prescrita e praticada. Esta última vincula-se à contextualização dos múltiplos saberes do cotidiano escolar, contribuindo para a construção de um saber próprio atravessado pela ação de professores e alunos. Segundo Soares (2012, p. 619), “o currículo prescrito não está apenas nos documentos que explicam e evidenciam as prescrições do Estado." A prescrição está também nas avaliações, nos livros didáticos e em diferentes formas de controle do currículo escolar, elaborado por gestores do Estado. Sendo assim, devemos nos perguntar: Quais as instâncias presentes no processo de prescrição? A comunidade escolar - professores, alunos, direção, funcionários da administração, profissionais da gestão e supervisão, etc. tem acesso participativo a este processo de elaboração? Como se dá a relação entre formação inicial e continuada dos professores e a atividade docente em sala? Dito de outro modo, como se articulam os saberes docentes e os embates entre estas modalidades curriculares?

Consoante Soares (2012, p. 625), o cotidiano escolar permite a crítica ao prescrito e a construção de uma prática curricular própria. Não obstante, na composição do currículo praticado há um conjunto de fatores que interagem entre si: o próprio currículo prescrito, os processos de avaliação institucional, os 
materiais didáticos (muitas vezes exteriores às intenções didáticas dos próprios professores), as expectativas de aprendizagem, a formação inicial e continuada, dentre outros.

Ao tomarmos estes pressupostos, buscamos neste artigo analisar as prescrições presentes na reforma curricular de $2003^{2}$ e $2008^{3}$ e suas implicações e desdobramentos para a construção de políticas públicas escolares para a efetivação da temática afroindígena nas escolas e a implementação e reconhecimento dos espaços etnoeducacionais ${ }^{4}$ indígenas e quilombolas e suas especificidades de ensino. Deste modo, compreendemos a inserção da temática afro-indígena nas escolas como materialização das reinvindicações históricas de movimentos sociais na luta contra o racismo estrutural na sociedade brasileira,

\footnotetext{
${ }^{2}$ Segundo a lei, houve a alteração da "Lei no 9.394, de 20 de dezembro de 1996, que estabelece as diretrizes e bases da educação nacional, para incluir no currículo oficial da Rede de Ensino a obrigatoriedade da temática "História e Cultura Afro-Brasileira", e dá outras providências." Segundo o decreto, "nos estabelecimentos de ensino fundamental e médio, oficiais e particulares, torna-se obrigatório o ensino sobre História e Cultura Afro-Brasileira. § 1o conteúdo programático a que se refere o caput deste artigo incluirá o estudo da História da África e dos Africanos, a luta dos negros no Brasil, a cultura negra brasileira e o negro na formação da sociedade nacional, resgatando a contribuição do povo negro nas áreas social, econômica e política pertinentes à História do Brasil. § 2O Os conteúdos referentes à História e Cultura Afro-Brasileira serão ministrados no âmbito de todo o currículo escolar, em especial nas áreas de Educação Artística e de Literatura e História Brasileiras. (...). Art. 79-B. O calendário escolar incluirá o dia 20 de novembro como 'Dia Nacional da Consciência Negra'. Brasília, 9 de janeiro de 2003; 182으 da Independência e 115o da República”. Disponível em: http://www.planalto.gov.br/ccivil 03/leis/2003/L10.639.htm. Data de acesso 02 de fev. de 2017.

3 Segundo esta lei, em alteração da Lei 9394/96, já modificada pela Lei 10639/03 :" O conteúdo programático a que se refere este artigo incluirá diversos aspectos da história e da cultura que caracterizam a formação da população brasileira, a partir desses dois grupos étnicos, tais como o estudo da história da África e dos africanos, a luta dos negros e dos povos indígenas no Brasil, a cultura negra e indígena brasileira e o negro e o índio na formação da sociedade nacional, resgatando as suas contribuições nas áreas social, econômica e política, pertinentes à história do Brasil. § 2ㅇ Os conteúdos referentes à história e cultura afro-brasileira e dos povos indígenas brasileiros serão ministrados no âmbito de todo o currículo escolar, em especial nas áreas de educação artística e de literatura e história brasileiras.” Disponível em: http://www.planalto.gov.br/ccivil_03/_ato2007-2010/2008/lei/111645.htm. Data de acesso 02 de fev. de 2017.

4 As comunidades etnoeducacionais indígenas foram oficialmente reconhecidas foram oficialmente reconhecidas pelo decreto presidencial 6861 de 2009, quando o governo federal estabeleceu uma situação jurídica específica às comunidades indígenas, baseado no princípio de gestão escolar autônoma e de valorização ao protagonismo ameríndio. Em consonância com o decreto de 2009, a portaria 1062, de 30 de outubro de 2013 do Ministério da Educação, instituiu-se o Programa Nacional de Territórios Etnoeducacionais, PNETEE (BERGAMASCHI \& SOUSA, 2015, p. 145)
} 
em favorecimento da inclusão de políticas públicas capazes de promover a equidade de direitos em respeito às especificidades identitárias étnicorraciais.

Nesse sentido, a reforma curricular propõe uma mudança de posturas, atitudes e valores que não dizem respeito somente à questão conteudística, mas à forma como os sujeitos escolares - professores, alunos, equipe pedagógica, funcionários administrativos, etc. - se veem na sociedade. Para Hebe Mattos (2003, p. 127) e Maria Regina Celestino de Almeida (2003, p. 25) não basta apenas acrescentar a temática, se continuarmos a tratar o indígena como elemento folclorizado, distante do seu contexto histórico-social ou se "festejamos" o Dia da Consciência Negra, reafirmando elementos de exotismo, com base na compreensão superficial do samba, da capoeira, das religiões de matrizes africanas e outras expressões culturais. Essas práticas escolares, que insistem em folclorizar as culturas afrobrasileiras e indígenas perpetuam, na verdade, posturas discriminatórias veladas pelo "elogio" exótico.

Kabengele Munanga (2010, p.193), ao tratar sobre as teorias raciais, assevera que o termo adquiriu cunho científico em fins do século XIX e início do século XX, quando as ciências humanas fizeram uso dos parâmetros do darwinismo biológico para entender as sociedades em suas diferenças. Segundo o viés evolucionista, as desigualdades entre as diferentes culturas eram explicadas com base em critérios etnocêntricos e a ação imperialista servia como pretexto para "civilizar" e "levar a evolução" a outros povos, através das políticas expansionistas promovidas pelas potências industrializadas da cultura europeia. Hoje em dia, o termo não se pauta mais neste aspecto biológico, mas em seu uso político e social, conforme as apropriações feitas em diferentes contextos históricos por diversos grupos sociais. Segundo o antropólogo, o racismo no século XXI se reconstrói “com base em outras essencializações, notadamente culturais e históricas e até aquelas consideradas politicamente 
corretas, como a etnia, a identidade e a diferença cultural." (MUNANGA, 2010, p. 193) Nesse sentido, o termo raça é pensado, neste discurso, pelo seu aspecto político e cultural, não pela atribuição biológica, como fora utilizado pelas teorias raciais e eugenistas. $\mathrm{O}$ autor também denuncia os crimes contra a humanidade causados pelas políticas segregacionistas, ancoradas em práticas racistas, tais como o nazismo, o fascismo e as apartheids da África do Sul e dos Estados Unidos.

Com efeito, o maior perigo entre nós, brasileiros, é não termos sensibilidade para decodificar as "manifestações do nosso racismo à brasileira", velado pela hipocrisia da crença na pretensa harmonia da diversidade étnica, também chamada de mito da "democracia racial" (MUNANGA, 2010, p.170). Sendo assim, "fica muito difícil arrancar do brasileiro de que ele é racista", pois "racista" é sempre o "outro" e nunca nós mesmos. A situação se agrava quando as práticas de discriminação são explicadas apenas pelo viés social, isto é, pelas condições de classe, em menosprezo do sentimento de superioridade/inferioridade que atravessam as relações étnicorraciais. O argumento das desigualdades raciais pelo viés exclusivamente materialista visa desqualificar as políticas afirmativas e sua busca pela implementação da equidade étnicorracial, através das iniciativas de diferenciações positivas.

Nilma Gomes (2005, p.140), ao tratar sobre as desigualdades raciais na educação, pondera que hoje a escola "está cada vez mais desafiada a enfrentar e a tratar pedagogicamente" a questão do racismo presente nas práticas e valores escolares, bem como no inconsciente coletivo do imaginário social de nossa sociedade. Por isso, o primeiro desafio consiste em superar a crença de que a função da escola está reduzida à transmissão de conteúdos, pretensamente neutros, desvinculados do seu contexto social. A escola está inserida em uma sociedade e cabe à ela enfrentar os conflitos e contradições reproduzidos pela 
sociedade, muitas vezes no interior das próprias práticas escolares. Por eu turno, é preciso compreender a educação como um processo também "formado por dimensões [pertinentes] à ética, às diferentes identidades, à diversidade, à sexualidade, às relações sociais, entre outras" (GOMES, 2005, p. 147). Isso significa entender o aprendizado como um processo mais amplo, ancorado na realidade, levando em conta os valores difundidos fora dos muros escolares para, desta forma, identificarmos a persistência de práticas discriminatórias vigente no "currículo oculto" 5 e os silenciamentos produzidos pelos currículos oficiais e praticados nas escolas.

Com efeito, a criação de estratégias de combate ao racismo nas escolas implica em observar, com cuidado, as atitudes dentro e fora do espaço escolar, isto é, os gestos discriminatórios sutis e extravagantes, as violências psicológicas e físicas causadas pelas posturas racistas, os silêncios, as omissões e a passividade ante as injustiças e desrespeito identitários. Devemos nos perguntar e refletir, diariamente, sobre as nossas formas de lidarmos com as ofensas raciais praticadas por alunos e, até mesmo, por professores e funcionários da escola. Há uma tentativa de conscientização e mobilização coletiva para superarmos as mazelas causadas pela violência étnicorracial nas culturas escolares?

Como o Plano Político Pedagógico (PPP) da escola lida com estas questões? São tratadas apenas de forma pontual nas datas comemorativas do calendário escolar (19 de abril e 20 de novembro)? De que modo enfrentamos os discursos segregacionistas, o racismo velado, o tratamento agressivo permeado de preconceitos reproduzidos, com tanta força, no ambiente escolar?

\footnotetext{
${ }^{5} \mathrm{O}$ currículo oculto pode ser entendido como o conjunto de habitus ou de normas sociais, princípios e valores transmitidos pela vivência cotidiana durante o processo de escolarização. No entanto, não se trata de um regimento explícito e não aparece formalmente em planos curriculares, mas possui legitimidade e força costumeira no ambiente escolar. Geralmente está ligado às coerções internas e às pressões extra-salas, tais como os mecanismos de controle e de exclusão social. Sobre a formação social dos currículos, ver: SACRISTÁN, 1999, p. 34; GOODSON, 1995, p. 27.
} 
Responder estas questões não é tarefa fácil e o exercício de reflexão deve ser feito ao longo de nossas atuações docentes, por outro lado, a implantação desta reforma não ficou a encargo somente dos professores, o Ministério da Educação e da Cultura (MEC), em parceria com a extinta Secretaria de Educação Alfabetização, Diversidade e Inclusão (SECADI) e com a UNESCO, iniciou uma série de ações para garantir a eficácia e a ingerência das leis 10.639/03 e 11.645/08. Dentre elas, podemos destacar:

A elaboração das Diretrizes Curriculares Nacionais para a Educação das Relações Étnico-Raciais e para o Ensino de História e Cultura Afro-Brasileira e Africana (2004), aprovada pelo Conselho Nacional de Educação;

A criação do Programa UNIAFRO (2008), em parceria com os Núcleo de Estudos Afro-brasileiros (NEABs), com o objetivo de fomentar ações voltadas para a formação inicial e continuada de professores da educação básica e para a elaboração de material didático específico no âmbito do Programa de Ações Afirmativas para a População Negra nas Instituições Federais e Estaduais de Educação Superior (Uniafro);

A avaliação dos materiais didáticos, em referência à contemplação da lei, através do Plano Nacional do Livro Didático (PNLD);

O incentivo à promoção de fóruns estaduais e municipais de educação e diversidade étnicorracial;

Oficialização do Programa de Ações Afirmativas (2005) em universidades federais, com intuito de ampliar o acesso de setores étnicos historicamente marginalizados no ingresso ao ensino público superior (GUIMARÃES, p. 2012, p. 66).

Essas medidas refletem, em parte, a luta permanente e cotidiana dos movimentos sociais contra as diferentes formas de racismo - seja no aspecto institucional, através da violência policial em áreas pobres de concentração 
populacional de negros - seja nas formas sutis, relacionadas aos discursos humorísticos e ao silenciamento da representatividade negra nos meios publicitários e artísticos da grande mídia.

A luta pela conscientização da questão étnica ultrapassa o âmbito escolar, sem deixar de fazer dele um instrumento estratégico de transformação das culturas discriminatórias em culturas de respeito e de reconhecimento da diversidade étnico-cultural em suas singularidades e modos diferentes de ser no mundo. A questão identitária, proclamada nas alterações curriculares de 2003 e de 2008, não diz respeito somente ao aspecto fenotípico ou as exterioridades físicas, mas principalmente como o indivíduo se vê representado e constrói a sua representação identitária no mundo pelo qual ele se insere. Nesse sentido, a identidade cultural perpassa pelas referências sociais e históricas dos seus modos de ser no mundo, isto é, as formas pelas quais este indivíduo recria e dialoga com suas memórias e com o seu passado social para criar os seus mecanismos de pertencimento (BARTH, 2000).

Com efeito, construir uma educação antirracista requer do professor de história não só a ruptura com a história linear, etnocêntrica e factual, pois uma abordagem das identidades étnicas e o reconhecimento de sua pluralidade exigem, sobretudo, uma mudança de postura das atitudes e valores capazes de decodificar e superar as práticas racistas tão arraigadas no inconsciente coletivo da sociedade brasileira. É preciso reconhecer que a legislação, embora signifique um passo importante, não é suficiente para tratar tais praticas de exclusão como crime, conforme postula o artigo quinto da Constituição Federal. ${ }^{6}$ No item a seguir procuramos tecer considerações acerca do papeis do estágio

\footnotetext{
6 Segundo a Constituição Federal: "Todos são iguais perante a lei, sem distinção de qualquer natureza, garantindo-se aos brasileiros e aos estrangeiros residentes no País a inviolabilidade do direito à vida, à liberdade, à igualdade, à segurança e à propriedade, nos termos seguintes: XLII - a prática do racismo constitui crime inafiançável e imprescritível, sujeito à pena de reclusão, nos termos da lei." Disponível em:
} 
supervisionado na formação identitária do professor de história e na construção das acepções de cidadania ampliada ${ }^{7}$ através de um ensino de história de inclusão da temática afro-indígena em sala de aula.

\section{A formação dos professores em comunidades etnoeducacionais e quilombolas}

O estágio supervisionado, conforme Pimenta e Lima (2012) deve ser entendido como uma ação coletiva voltada para ação docente capaz de articular, de forma integrada, os espaços da escola, universidade, poderes públicos e a comunidade. Tidos como um dos pontos nodais da formação docente, o estágio curricular deve propiciar ao estagiário um espaço para reflexão, ação, intervenção, problematização e proposição de ideias que superem as criticas vazias e concentradas em pessimismos imobilizantes da prática de ensino para, assim, viabilizar projetos com vistas à contextualização da prática docente e da escola enquanto espaço institucional vinculada a políticas públicas educacionais. Deste modo, todos os sujeitos envolvidos professor coordenador (universidade), regentes escolares, diretores, gestores educacionais, estagiários, alunos - são coparticipes e têm um papel importante neste processo.

Nesse sentido, a comunicação e a escuta dos anseios da comunidade escolar precisam se tornar atitudes contínuas por parte da orientação desta disciplina para que as reais demandas escolares possam ser identificadas, de

http://www.planalto.gov.br/ccivil_03/constituicao/constituicao.htm. Data de acesso em 02 de fev. de 2017.

${ }^{7}$ A noção de cidadania ampliada se difere da cidadania clássica, pautada no princípio de igualdade, por se inserir no pressuposto de justiça de equidade e considerar, a partir da política do reconhecimento, a alteridade e o direito à diferença de grupos de minorias sociais (mulheres, negros, homossexuais, etc.) que buscam a reivindicação dos seus direitos em suas singularidades. Esta concepção de cidadania adquiriu notoriedade com a emergência do multiculturalismo e da fragmentação dos movimentos sociais da esquerda (MAGALHÃES, 2003, p. 168). 
modo que esta experiência sirva como ponto de partida e de chegada para a teorização da prática profissional, num ir e vir dialético entre o refletir o e o fazer docente. Consoante Monteiro (2007, p. 227), os professores mobilizam saberes com autoria de produção, em contraposição à racionalidade técnica que enxerga no professor o profissional que transmite conhecimentos externos a ele próprio, desconsiderando suas subjetividades, leituras de mundo e capacidade de diálogo e de interação com os alunos, também sujeitos do conhecimento.

Com base nestes apontamentos é preciso considerar a formação de professores e o estágio supervisionado em história em comunidades indígenas e quilombolas a partir do diálogo intercultural, do reconhecimento do protagonismo histórico e da afirmação identitária destes povos. A Lei 11.645/08, responsável pela materialização das reivindicações históricas de movimentos sociais, como o Movimento Negro Unificado (MNU) e Movimento das Nações Indígenas (MNI), serviu de anteparo à discussão da escola indígena e da educação escolar quilombola, enquanto direitos sociais sustentados no respeito à diferença e na valorização dos processos próprios de produção do conhecimento.

Quando tratamos da identidade, devemos considerá-la como processo dinâmico, mutável e interacional, em construção permanente, conforme as contingências históricas e agenciamento protagonizado por seus sujeitos em contato. Nesse sentido, concordamos com F. Barth (2000: 25) a despeito da mobilidade das identidades étnicas, isto é, do seu papel intercambiável, fluído e adaptável de acordo com os aspectos situacionais e dos referenciais contextuais auto-atribuitivos e externos em relação aos modos de pertencimento em um grupo cultural.

Deste modo, o processo de formação de professores em história exige sensibilidade e uma problematização atenta capaz de criar de uma postura de 
alteridade que habilite o futuro educador para lidar com contextos escolares multiculturais diferenciados, como as comunidades indígenas e quilombolas. Um dos principais pontos para se trabalhar com a questão multiétnica, dentro e fora da escola, diz respeito à desconstrução de estereótipos historicamente elaborados em torno da representação dos sujeitos não brancos da sociedade. Exemplo disto pode ser notado na viabilização de uma postura coletiva de desnaturalização das imagens cristalizadas acerca do "indígena" do "negro" e do "mestiço" em nossas práticas cotidianas, muitas vezes tangenciadas por posturas discriminatórias reproduzidas, de forma contundente, pelo discurso hegemônico.

As representações estigmatizantes destes grupos evolvem desde o "elogio exótico" - a sensualidade da mulata, a malandragem do negro passista ou do jogador de futebol - até as deformações explicitamente ofensivas - a imagem do índio congelada no tempo, a "preguiça" do caboclo, a "vadiagem" e a "degeneração" do mestiço. Com efeito, estas construções imagéticas não são estanques, atemporais - embora o discurso dogmático tende a "naturalizá-las" - constituindo-se, assim, em atributos históricos, condicionados às significações dadas pelos espaços de experiências e horizonte de expectativas dos sujeitos (KOSELLECK, 2006).

A despeito das representações históricas dos povos indígenas, Maria Regina Celestino de Almeida (2003: 27) pondera que estas foram construídas em função dos interesses dos colonizadores e, posteriormente, do projeto de construção de identidade nacional, após o período da independência política em 1822. Com a institucionalização do Instituto Histórico Geográfico Brasileiro (IHGB) e do Colégio D' Pedro II (1837), o Estado incentivou oficialmente a confecção de uma memória nacional de exaltação à ação da Coroa e à "missão civilizatória" da colonização. Neste discurso hegemônico criou-se, a partir de 
Von Martius, ${ }^{8}$ o mito da fusão das três raças, em que o negro e o índio seriam coadjuvantes do processo histórico protagonizado pelo elemento colonizador. Nesta abordagem, o indígena aparece como "massa amorfa e inerte à disposição dos missionários" ou como herói romantizado, com suas plumas e cocar, em alianças com portugueses, como representado pelo personagem Peri de José de Alencar (ALMEIDA, 2003: 27). Segundo esta perspectiva, os indígenas eram considerados povos sem história, presos no passado, à uma tradição estática. Seriam, de acordo com Varnhagen", outro intelectual de referência na época, "povos na infância".

Tal imagem congelante do indígena na história, ainda se faz presente no senso comum e nas representações midiáticas, quando se reproduz as imagens do "índio puro" e "não puro", como se o isolamento cultural ou a estagnação no tempo fossem situações possíveis para qualificar alguma organização cultural como genuína ou falsa. De acordo com Giovani José da Silva (2015) esta desqualificação à identidade indígena se faz tanto pela imagem fossilizada e ahistórica dos seus povos, como pelo discurso da aculturação e desaparecimento fatídico das culturas indígenas. Sendo assim, o argumento da aculturação unilateral obscurece os espaços de manobra e de negociação desses grupos para tomar resoluções sobre seus destinos, ainda que diante as situações adversas e desiguais de poder. Do mesmo modo, a crença na extinção inevitável não consegue explicar o aumento demográfico das populações indígenas, decorrente do crescimento vegetativo e da autoafirmação identitária dos grupos étnicos. (SILVA, 2015: 26).

\footnotetext{
${ }^{8}$ Ver a obra "Como se deve escrever a história do Brasil", monografia aprovada pelo concurso do IHGB em 1840 cuja proposta era elaborar uma escrita historiográfica capaz de responder questões sobre os anseios acerca da identidade nacional.

${ }^{9}$ Cf.: VARNHAGEN, 1962, p. 42.
} 
Nesse sentido, as práticas de folclorização ${ }^{10}$ se perpetuam em ambientes escolares, desde a tenra infância, quando nos é ensinado que o índio é uma figura pertencente ao passado, adorador de Tupã, nu, com cachimbo na boca, cocar à cabeça e arco e flecha nas mãos. Nesse sentido, prevalece durante o ano letivo, quando não o silêncio perturbador, a recriação de imagens estereotipadas do indígena em temas pontuais, como os "episódios do descobrimento."

Com o objetivo de romper esta cultura do silencia e da exotização, o ensino de história em comunidades indígenas tem como amparo legal as Diretrizes Nacionais Curriculares Para a Educação Escolar Indígena, aprovadas pelo Conselho Nacional de Educação em 2012. Tais diretrizes reforçam o direito à diversidade, à autonomia cultural e ao acesso à educação bilíngue, assegurado pelo Artigo 231 da Constituição Federal (1988). Além disso, o documento ratifica o pluralismo de ideias e de concepções pedagógicas presentes na Lei de Diretrizes e Bases da Educação (1996), ao valorizar a experiência extraescolar como fonte de conhecimento e assegurar o desenvolvimento de currículos e programas específicos voltados para as comunidades indígenas, em respeito às suas escolhas e autogestão de aprendizagem. Sendo assim, as diretrizes rompem com a política de educação tutelar - tradicionalmente presente em órgãos indigenistas, como o extinto Serviço de Proteção ao Índio (SPI) e a Fundação Nacional do Índio (Funai) - para reverberar a capacidade de auto-representação jurídica, cultural e social destes povos. Nesta perspectiva, o indígena deixa de ser pensado como categoria provisória, em vias de integração e civilização, para ser respeitado em suas especificidades e necessidades culturais e históricas.

Por seu turno, toma-se como pressuposto o princípio da interculturalidade e do protagonismo histórico dos sujeitos historicamente

\footnotetext{
${ }^{10}$ Sobre as críticas em torno do trabalho dos folcloristas, ver: THOMSON, 1998, p. 17.
} 
marginalizados mediante a conquista e reivindicação aos direitos de acesso aos territórios etnoculturais, como também à educação escolar indígena e à construção da narrativa histórica de suas memórias, identidades, valores, religiosidades e outras práticas culturais. Com efeito, o estágio supervisionado nestas comunidades deve levar em conta a prioridade da formação e profissionalização dos professores indígenas. Isso quer dizer que uma escola baseada no diálogo intercultural só será possível se tivermos professores pertencentes à própria comunidade como interlocutores da mediação entre os seus saberes tradicionais e aqueles curriculares referentes à Base Nacional Comum. Ademais, o Estado deve se imbuir da responsabilidade de regularizar o magistério indígena, enquanto categoria profissional cuja formação exige conhecimentos e habilidades específicas ao pertencimento identitário étnico destas comunidades, além dos conteúdos da Base Comum. Deste modo, a formação inicial e continuada precisa criar condições para que estes professores se especializem na construção de saberes atentos aos códigos culturais de seus pertencimentos.

Sendo assim, o estágio viabiliza a oportunidade para que a formação profissional se estabeleça como um espaço propício à investigação da prática de ensino em contextos escolares específicos, tornando as comunidades etnohistóricas o ponto de partida e de chegada para a reflexão da ação docente em ambientes específicos multiculturais e multilinguísticos. Com efeito, a aproximação entre universidade/comunidades etnoeducacionais e quilombolas ou outros espaços diversos oportuniza a análise do contexto sociocultural em que os saberes escolares e a ação docente se constituem enquanto prática cotidiana desses grupos. Deste modo, consideramos que a produção do conhecimento ultrapassa, necessariamente, o espaço físico da sala 
de aula na qualidade de campo de construção do saber (PIMENTA \& LIMA, 2012).

Todavia, pretende-se compreender a ação do professor indígena ou quilombola em sua historicidade de pertencimento cultural, analisando seus modos de ensinar articulados com suas visões de mundo, formas de pertença e expectativas perante sua ação educacional e a inserção da escola indígena ou quilombola em uma sociedade permeada por conflitos étnicos e de negação da sua existência em espaços tradicionalmente hegemônicos e excludentes. Outrossim, o processo de realização do estágio nessas comunidades envolve a ação coletiva entre professores em formação, regentes das escolas, alunos em processo de aprendizado e supervisores da disciplina de estágio. A intervenção acontece durante o espaço de observação etnográfica, elaboração de projetos e regência de aulas planejada, realizada de acordo com as demandas e necessidades didáticas específicas, acordadas entre o professor da escola e o docente em formação. Não obstante, o estágio supervisionado em comunidades etnoeducacionais e quilombolas deve estar atento aos "nexos e relações da escola com o sistema social mais amplo" (PIMENTA \& LIMA, 2012, p. 121).

A análise experiencial desenvolvida pelo processo de estagiar precisa abranger os significados do que é ser sujeito, professor, aluno em uma escola assentada no princípio da interculturalidade. O que a ação docente representa numa sociedade que invisibiliza e estigmatiza o pertencimento e as comunidades indígenas e quilombolas? Como o Estado se relaciona com estas comunidades e quais as políticas públicas educacionais empregadas, de fato, nestes contextos? Como a questão da tolerância, da pluralidade cultural e do direito à diferença é tratada em escolas etnoeduacionais e quilombolas fora delas? Como as identidades socioculturais do ser professor nestes territórios são significadas diariamente dentro e fora das comunidades? 
Estas questões podem ser norteadoras da reflexão da epistemologia da prática e atravessam os questionamentos acerca da formação identitária do professor de história do Ensino Básico. Segundo as Diretrizes Curriculares Nacionais para a Educação Quilombola (2012), os sistemas de ensino - em regime de cooperação - têm por dever assegurar a atividade docente nestas comunidades exercida, preferencialmente, por profissionais pertencentes à própria comunidade quilombola. Nesse sentido, o estágio supervisionado feito em articulação entre as Instituições de Ensino Superior (IES) e a comunidade escolar - deve privilegiar o estudo da "memória, ancestralidade, oralidade, corporeidade, estética e do etnodesenvolvimento produzido pelos quilombolas ao longo do seu processo histórico, político, econômico e sociocultural" (DCN's para a Educação Escolar Quilombola, 2012, p. 470).

Ademais, as instituições de ensino superior, em parceria com os poderes públicos, têm por incumbência assegurar aos alunos estagiários as condições de transporte e alojamento para que o estágio curricular em áreas de comunidade quilombola seja realizado. Outras ações de estímulo e aprimoramento da formação do professor em territórios etnoeducaionais e quilombolas podem ser colocadas como prioridades na confecção do regimento do Projeto Pedagógico do Curso (PPC) de Licenciatura, como também do Projeto Politico Pedagógico (PPP) das escolas em questão. A criação de Grupos de estudos, projetos de extensão universitária e o fortalecimento do estágio como campo de pesquisa viabilizam frentes promissoras para o desenvolvimento de investigações acerca dos modos de vida destas comunidades, suas historicidades, vivências de memórias da escravidão, consanguinidade, rituais festivos e processos de luta pelo reconhecimento por parte do Estado de suas relações culturais e identitárias de ocupação da terra (territorialidade). 
Nilma Gomes e Kabengele Munanga (2006, p. 71) afirmam que o termo "quilombo" - originário da língua umbundo dos povos ovimbundos significava a formação de agrupamentos militares "itinerantes", táticas de guerra utilizadas pelos povos jagas ou imbangalas (Angola). Na diáspora atlântica, o termo adquiriu outras leituras, redefinindo-se de acordo com as imposições e necessidades situacionais colocadas pelo contexto da escravidão no Novo Mundo. Flávio dos Santos Gomes (2006) pondera que os quilombos ou mocambos comportavam uma sociabilidade e um intercâmbio cultural plural. Ao contrário do que se pensava, não eram redutos isolados da sociedade escravista, ainda que se situassem em áreas rurais (lembrando que havia também quilombos urbanos). $\mathrm{O}$ autor chama atenção para o cuidado que devemos ter em relação às generalizações perigosas, pautadas numa dicotomização rígida entre escravidão versus resistência, cativeiro versus quilombo. Consoante Gomes (2006, p. 88), quilombo e senzala formavam uma "complexa rede de convivências, arranjos e interesses". Nesse sentido, o "aquilombamento podia ser uma extensão da organização social das comunidades de senzalas" no que diz respeito às lutas pela ampliação dos espaços de autonomia, dos laços de solidariedade e de consanguinidade, como também dos direitos costumeiros conquistados mediante o conflito aberto e/ou o processo de negociação cotidiana contra o mandonismo do poder senhorial. (GOMES, 2006, p.301).

Não obstante, o redimensionamento da historicização do quilombo escravista, em sua multiplicidade étnica e cultural, contribuiu para o exercício da diacronia histórica, na medida em que a contextualização dos processos de expropriação das terras quilombolas, em função do fortalecimento histórico dos latifúndios, nos permite o alargamento da compreensão acerca do redimensionamento dos quilombos em sua contemporaneidade. Assim como a 
etnicidade indígena, a identidade quilombola não se constitui de forma estática no tempo. É preciso compreender a movimentação histórica e os contatos interculturais entre seus membros e suas experiências na sociedade atual. Isso significa que o diálogo e a vivência com as tradições não são entendidas em oposição à modernidade, mas em processo de redefinição constante colocada pela experiência do tempo presente (CANCLINI, 2008, p. 67). Por isso não se pode perder de vista o aspecto da mobilidade e historicidade pertencente à construção das identidades étnicas em situações de contato cultural. Todavia, os direitos à diferença e à territorialidade (uso comum da terra) devem ser vistos como condições imprescindíveis para a continuidade e existência do próprio grupo.

O estágio supervisionado em comunidades quilombolas se institui como espaço fecundo para discutirmos os desafios dos professores, alunos e demais pertencentes à comunidade etnoeducacional no tocante aos enfrentamentos cotidianos de situações de racismo ambiental (negação do direito ao uso da terra), bem como das práticas discriminatórias assentadas no mito da democracia racial, isto é, da ideia de que o racismo não existe no Brasil. Contudo, o ensino de história engajado em uma formação de educação étnicorracial é capaz de propor reflexões, ações e transformações dentro do próprio cotidiano escolar. Isso ocorre na medida em que tal campo disciplinar se abre como terreno promissor para instigar questionamentos sobre os significados da cidadania na contemporaneidade, proporcionando aos alunos subsídios para que estes se sintam agentes ativos no contexto em que vivem. Além disso, a disciplina cria condições propícias para o desenvolvimento do raciocínio histórico - junto às habilidades de desconstrução de preconceitos, discursos pré-estabelecidos - com vistas ao entendimento da construção 
histórica dos direitos e da luta pela ampliação destes pelos movimentos de combate à exclusão etnicorracial.

Com efeito, é possível historicizar as próprias noções de cidadania e a necessidade de atualizar o conceito e suas práticas conforme as reinvindicações emergenciais dos embates do nosso tempo presente. A partir deste exercício, torna-se pertinente o aprimoramento dos processos de conscientização por direitos e deveres dentro de uma sociedade, algo que não começa e nem termina dentro do espaço escolar, mas faz deste um importante canal para se discutir e tratar, de forma comprometida com os valores democráticos, a importância de se desenvolver noções de alteridade e de reconhecer no "outro" a portabilidade de cidadania cuja constitucionalidade ${ }^{11}$ confere.

Nesse sentido, trazer à tona a importância da escola, mais especificamente do ensino de história, como espaços cruciais para o debate acerca das concepções da interculturalidade como princípio da formação escolar é fazer frente à retomada conservadora presente nas políticas públicas pelas quais vem sendo impostas na esfera educacional. Deste modo, este também é momento para reafirmar a legislação de uma educação de inclusão étnicorracial, a própria ação docente e o exercício do aprender, como ações políticas, indissociadas das questões emergenciais do seu contexto histórico. ${ }^{12}$

A inserção das temáticas como etnicidade e educação antirracista visa dar visibilidade aos sujeitos historicamente discriminados tanto nas narrativas das memórias oficiais escolares, quanto no exercício efetivo de suas ações

\footnotetext{
${ }^{11}$ A formação para uma cidadania de cunho democrático e de integração dos direitos humanos, como metas de ensino, passou a ser uma preocupação das políticas públicas educacionais durante a insurgência dos debates promovidos pela Constituinte de 1988, com o processo de redemocratização. A ressonância desses princípios se consolidou nos artigos $6^{\circ}$ da Constituição Federal, ao tratar sobre os direitos sociais, e em seus artigos 205 ao 214, quando a legislação se debruça em uma seção dedicada à educação (BRASIL, Constituição Federal, 1988).

${ }^{12}$ Nesse sentido, concordamos com Hannah Arendt (1995), ao tomar a definição da dimensão política como um conceito amplo, para além do que entendemos como politicamente instituído. Outrossim, toda ação é uma ação política, na medida em que a condição humana é politicamente ativa, por sermos dotados de fala, de relações, de significações e de leituras de mundo. Fica claro, então, que não se pode fazer uma relação direta e simplista entre esta dimensão com ideologias partidárias.
} 
participativas nos campos de poder institucionalizados da sociedade. Todavia, um dos maiores desafios para a construção de um ensino de história comprometido com a formação para à cidadania e para a conscientização histórica diz respeito ao enfrentamento das práticas abusivas de discriminação dentro e fora da escola, como os processos de exclusão e violência dos grupos considerados historicamente vulneráveis.

\section{Considerações finais}

A reforma curricular de 2003 e 2008 (anteparo para a formulação das DCNs para a educação escolar indígena e quilombola) propõe uma mudança de posturas, atitudes e valores que não dizem respeito somente à questão conteudística, mas à forma como os sujeitos escolares - professores, alunos, equipe pedagógica, funcionários administrativos, etc. - se veem na sociedade. Não basta apenas acrescentar a temática, se continuarmos a tratar o indígena distante do seu contexto histórico-social ou se "festejamos" o Dia da Consciência Negra, reafirmando elementos de exotismo, com base na compreensão superficial do samba, da capoeira, das religiões de matrizes africanas e outras expressões culturais. Essas práticas escolares, que insistem em folclorizar as culturas afrobrasileiras e indígenas, nada mais fazem do que perpetuar posturas discriminatórias veladas pelo "elogio" exótico. Os sujeitos, nesta abordagem, são extraídos de suas especificidades e historicidades e colocados num plano mítico de memórias: é a criança que pinta o rosto e usa cocar no dia do Índio, ou a reverência cultivada ante a sensualidade da "mulata" do samba. São construções imagéticas baseadas em caricaturas que reforçam a estereotipagem desses segmentos em suas representatividades na sociedade. Sendo assim, tais práticas costumam "racializar" a abordagem ou 
naturalizam aquilo que pertence ao terreno cultural, por isso a distorção presente na afirmação de que o talento na arte do futebol, do carnaval e do samba está no "sangue do brasileiro" de procedência negra.

\section{Fontes}

BRASIL, Constituição da República Federativa do Brasil de 1988. Brasília, DF.

BRASIL, Lei de Diretrizes e Bases da Educação, Lei 9394/96. Brasília: Congresso Nacional, 1996.

BRASIL, Parâmetros Curriculares Nacionais. Brasília: MEC/SEF, 1998.

BRASIL, Diretrizes Curriculares Nacionais para a Educação das Relações Étnicorraciais e para o Ensino de História e Cultura Afro-Brasileira e Africana, Brasília: CNE, 2004.

BRASIL, Decreto Presidencial $n^{\circ}$ 6.861, de 27 de maio de 2009 (2009a). Dispõe sobre a

Educação Escolar Indígena, define sua organização em Territórios Etnoeducacionais e dá outras providências. Brasília, DF.

BRASIL, Portaria 1062, de 30 de outubro de 2013 (2013). Institui o Programa Nacional dos Territórios Etnoeducacionais - PNTEE. Brasil: Ministério da Educação e Cultura.

BRASIL, Diretrizes Curriculares Nacionais para a Educação Escolar Quilombola. Brasília: CNE, 2012.

BRASIL, Diretrizes Curriculares Nacionais para a Educação Escolar Indígena. Brasília: CNE, 2012.

\section{Referências}


ALMEIDA, Maria Regina Celestino de. Identidades étnicas e culturais: novas perspectivas para a história indígena." In.: ABREU, M. \& SOIHET, R. (Orgs.). Ensino de História. Conceitos, temáticas e metodologias. Rio de Janeiro: Casa da Palavra, 2003, pp. 25-37.

ARENDT, H. A Condição Humana. Trad. Roberto Raposo. 7. ed. Rio de Janeiro: Forense Universitária, 1995.

BARTH, F. O guru, o iniciador e outras variações antropológicas. Tomke Lask (org.) Rio de Janeiro: Contra Capa, 2000.

BERGANASCHI, M. A., SOUZA, F. B. Territórios etnoeducacionais: ressituando a educação escolar indígena no Brasil. In.: Pro-posições. V. 26, n. 2 (77), p. 143-161, mai./ago. 2015.

BRIGHENTI, Clóvis Antonio. "Movimento Indígena no Brasil". In.: WITTMANN, Luisa Tombini (Org.). Ensino (d)e História Indígena. Belo Horizonte: Autêntica, 2015, pp. 143-176.

CANCLINI, Nestor. Culturas Híbridas: estratégias para pensar e sair da modernidade. São Paulo: Edusp, 1998

GOMES, Nilma Lino. “Educação das Relações Raciais: Refletindo algumas estratégias de atuação. “ In.: MUNANGA, K. (org.) Superando o racismo na escola. 2ª Ed. Brasília: Ministério da Educação/SECAD, 2005, pp. 143-154.

GOMES, Nilma Lino \& MUNANGA, K. O Negro no Brasil de Hoje. São Paulo: Global, 2006.

GOMES, Flávio dos Santos. Histórias de quilombolas: Mocambos e comunidades de senzalas no Rio de Janeiro, século XIX. São Paulo: Cia. das Letras, 2006.

GOODSON, I. Currículo, teoria e prática. Petrópolis: Vozes, 1995. 
GUIMARÃES, Selva. “O estudo da história e da cultura afro-brasileira e indígena”. In GUIMARÃES, S. Didática e Prática de Ensino de História. Experiência, reflexões e aprendizados. 13를 Ed. Campinas-SP: Papirus, 2012, p.73-90.

KOSELLECK, Reinhart. Futuro Passado: contribuição à semântica dos tempos históricos. Rio de Janeiro: Contraponto: 2006.

MAGALHÃES, Marcelo de Souza. "História e Cidadania: por que ensinar história hoje?". In.: ABREU, M. \& SOIHET, R.. Ensino de História: conceitos, temáticas e metodologia. Rio de Janeiro: Casa da Palavra, 2003, pp. 168-186.

MONTEIRO, Ana Maria. Professores de História. Entre saberes e práticas. Rio de Janeiro: Mauad X, 2007.

MUNANGA, Kabengele. “Teoria Racial e Relações Raciais no Brasil." In.: Cadernos Penesb - Periódico do Programa de Educação sobre o Negro na Sociedade Brasileira FEUFF. Niterói/RJ: UFF, 2010, pp. 169-204.

PEREIRA, Amilcar Araújo. “Movimento Negro no Brasil Republicano". In.: Cadernos Penesb - Periódico do Programa de Educação sobre o Negro na Sociedade Brasileira FEUFF. Niterói/RJ: UFF, 2010, pp. 153-160.

PIMENTA, Selma Garrido \& LIMA, Maria Socorro Lucena. Estágio e Docência. $7^{7^{a}}$ Ed. São Paulo: Cortez, 2012.

SACRISTÁN, J. G. “Currículo e diversidade cultural”. In: SILVA, T.T. e MOREIRA, A. F. (Orgs.). Territórios contestados. Petrópolis: Vozes, 1995.

SOARES, Olavo. “Os currículos para o ensino de história: entre a formação, o prescrito e o praticado". In.: Antíteses, v. 5, n. 10, p. 613-634, jul/dez. 2012.

SILVA, Giovani José da. "Ensino de História Indígena". In.: WITTMANN, Luisa Tombini (Org.). Ensino (d)e História Indígena. Belo Horizonte: Autêntica, 2015, pp. 21-46. 
THOMSON, E. P. Costumes em Comum. Estudos sobre a cultura popular tradicional. São Paulo: Companhia das Letras, 1998.

VARNHAGEN, Francisco A. A História Geral do Brasil. São Paulo: Melhoramentos, $1962[1864]$. 